\author{
Military Technical College \\ Kobry El-Kobba \\ Cairo, Egypt
}

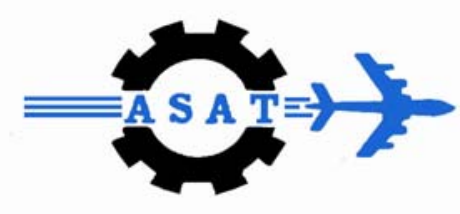

12-th International Conference

on

Aerospace Sciences \&

Aviation Technology

\title{
PREDICTION OF HYBRID COMBUSTION BOUNDARY LAYER PARAMETERS
}

\author{
A. EL-S MAKLED*
}

\begin{abstract}
The hybrid combustion phenomenon is more complex than the case of solid or liquid combustion. An understanding of hybrid combustion is dependent upon understanding of the interrelationships between the boundary layer zones characteristics and fuel grain geometry during burning time and along fuel grain.

The main objectives of the article are to predict hybrid combustion boundary layer geometry and characteristic parameters variation with fuel grain length during combustion. Specially, the relation between flame zone (propagation) position and regression rate change values during combustion. Based on this mathematical model, a computer code was implemented to identify the hybrid combustion boundary layer (BL) parameters.

The comparison between Schlieren photograph of Plexiglas-oxygen flat plate burner and computational results show good agreement. The presented code can be considered as a powerful tool for the design, analysis and can be used to evaluate quantitatively the effect of changes in various design parameters of hybrid rocket motor.
\end{abstract}

\section{KEY WORDS}

Hybrid propulsion, internal ballistics, regression rate, boundary layer.

\section{INTRODUCTION}

In a previous work, the variations of hybrid rocket motor parameters (pressure $P_{c}$, thrust $F$, specific impulse $I_{s p}$, regression rate $\dot{f}_{f u}$, fuel grain port diameter $d_{p o}$, and average oxidizer-to-fuel ratio O/F) with firing time, are analyzed and verified [1].

One of the most difficult hybrid parameters to evaluate is the regression rate of the hybrid combustion, this parameter must be described throughout the firing duration to simulate boundary layer performance parameters.

Hybrid combustion typically occurs in a thin layer of flame within the turbulent boundary layer. G. Marxman and co-workers [2,3] have developed the most

\footnotetext{
${ }^{*}$ Egyptian Armed Forces
} 
elaborated theory. Their analysis is based on the boundary layer combustion scheme Fig. 1, which is used up until now.
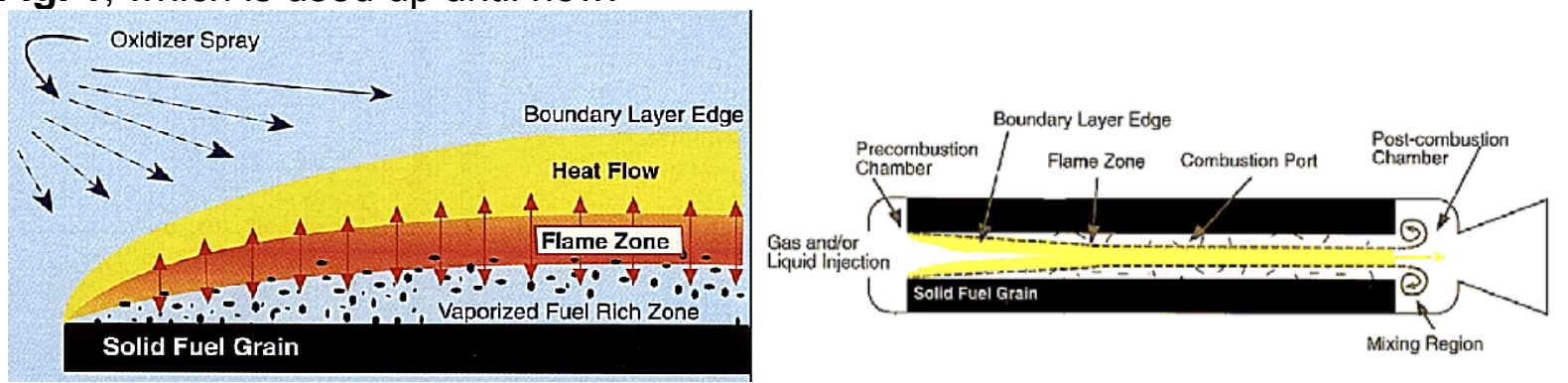

Fig. 1 Boundary layer Hybrid combustion scheme

Solid fuel is partly decomposed and evaporated (gasified) at the solid regression surface by convective plus radiative heat transfer and diffuses toward the centerline of the combustion volume. Simultaneously, gaseous oxidizer diffuses from the centerline through the turbulent boundary layer. At a point where the ratio of oxidizer to fuel concentration (O/F ratio) is somewhat on the fuel-rich side of a stochiometric, combustion occurs in a layer whose thickness is of the order of $15 \%$ of the boundary layer thickness, depending on operating conditions [2]. Figure 2 shows a schlieren photograph indicating the flame position for Plexiglas-oxygen burner, which is substantially close to the fuel surface than to the edge of the boundary layer [2].

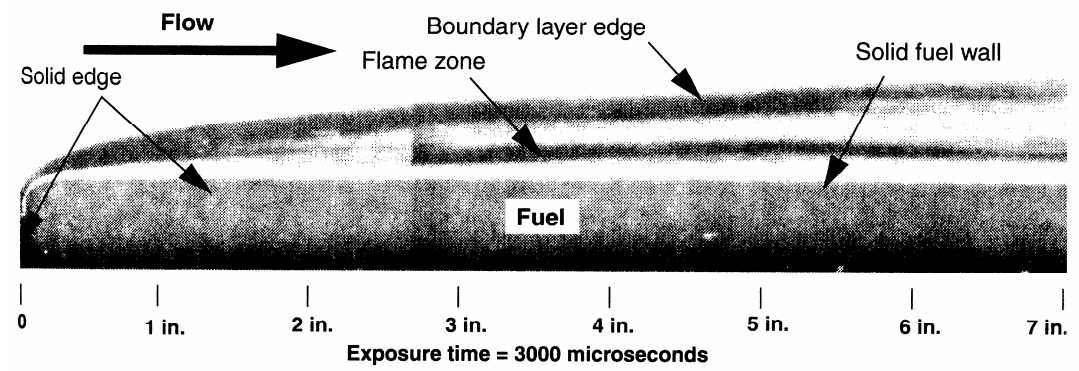

Fig 2 Schlieren photograph of Plexiglas-oxygen flat plate combustion burner [2]

According to this model the boundary layer comprises two zones, one above the flame (oxidizer rich and temperature and velocity gradient are opposed in direction), and another below the flame (fuel rich and the gradients are in the same direction).

The dependence of $\dot{\mathrm{r}}_{\mathrm{fu}}$ on convective heat transfer $\dot{\mathrm{Q}}_{\mathrm{c}}$ and radiative heat transfer $\dot{\mathrm{Q}}_{\mathrm{r}}$ from a thin diffusion flame zone to the solid surface is described by [3],

$$
\rho_{\mathrm{v}} \dot{\mathrm{r}}_{\mathrm{fu}}=\rho_{\mathrm{fu}}(1-\mathrm{k}) \dot{\mathrm{r}}_{\mathrm{fu}}=\left(\frac{\dot{\mathrm{Q}}_{\mathrm{c}}}{\mathrm{h}_{\mathrm{veff}}}\right)\left[\left(\frac{\dot{\mathrm{Q}}_{\mathrm{r}}}{\dot{\mathrm{Q}}_{\mathrm{c}}}\right)+\mathrm{e}^{\left.-\frac{\dot{\mathrm{Q}}_{\mathrm{r}}}{\dot{\mathrm{Q}}_{\mathrm{c}}}\right]}\right.
$$

Where $\quad \dot{\mathrm{Q}}_{\mathrm{c}}=0.036\left(\frac{\dot{\mathrm{m}}_{\mathrm{g}}}{\mathrm{A}_{\mathrm{po}}}\right)^{0.8}\left(\frac{\mathrm{x}}{\mu}\right)^{-0.2} \mathrm{~h}_{\mathrm{veff}} \beta^{0.23} \quad$ and $\quad \dot{\mathrm{Q}}_{\mathrm{r}}=\alpha \varepsilon \mathrm{T}_{\mathrm{r}}^{4}\left(1-\mathrm{e}^{-\alpha \mathrm{N}}\right)$

where

$\rho_{\mathrm{v}} \quad$ bulk density of volatile component of fuel grain

$\rho_{f u} \quad$ solid fuel grain density

$h_{\text {veff }}$ the effective heat of gasification of solid phase 
$\mathrm{k} \quad$ mass fraction of non-volatile surface material

$\dot{\mathrm{m}}_{\mathrm{g}} \quad$ total gas flow rate

$A_{\text {po }}$ effective port area, cf. Eq. 11

$\alpha \quad$ empirical radiation coefficient

$\varepsilon \quad$ emissivity of the fuel grain surface

$\mathrm{T}_{\mathrm{r}} \quad$ effective radiation temperature

$\mathrm{N}$ radiation parameter

$\mu \quad$ dynamic viscosity of combustion gases

$\mathrm{x}$ distance on longitudinal coordinate of fuel grain port

$\beta \quad$ mass transfer number cf. Eq. 12

In fact, the rate of gasification "regression rate" of the solid fuel surface depends upon heat transfer from the boundary layer. This means the $\dot{r}_{f u}$ is closely coupled to total

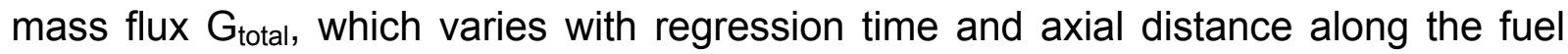
grain channel $L_{f u}$ and another parameters. Thus a semi-empirical formula of $\dot{r}_{f u}$ is given by

$$
\begin{aligned}
& \dot{\mathrm{r}}_{\mathrm{fu}}=0.036 \frac{\mathrm{G}_{\mathrm{tot}}^{0.8}}{\rho_{\mathrm{fu}}}\left(\frac{\mu}{\mathrm{x}}\right)^{0.2} \beta^{0.23} \\
& \text { where } \quad \mathrm{G}_{\mathrm{tot}}=\left(\frac{\dot{\mathrm{m}}_{\mathrm{g}}}{\mathrm{A}_{\mathrm{po}}}\right)
\end{aligned}
$$

Equation (2) was simplified experimentally. To be written as,

$$
\dot{r}=a G_{t o t a l}^{n} L_{f u}^{m}
$$

where $\quad a, n, m$ a regression rate constant

\section{HYBRID COMBUSTION BOUNDARY LAYER MODEL}

\section{1 Basic Assumptions of Model}

Theoretical equations have been used to predict hybrid combustion boundary layer parameters model of tubular channel from fundamental analysis of flat-plate slab burner.

The following major assumptions have been made for flat plate:

- grain regression rate is controlled by heat transfer from the diffusion flame,

- flame zone is infinitely thin,

- oxidizer enters port as a uniform gaseous stream,

- no heat transfer into subsurface region of solid grain and

- pressure is constant along the plate and varies only with time.

\subsection{Boundary Layer Parameters}

The complete hybrid combustion typically occurs in a thin layer of flame within boundary layer over the solid fuel regression surface. The formulation of a hybrid combustion boundary layer theory requires consideration of the process of heat transfer from the flame to the wall and internal ballistics parameters as Eq. (1).

The important characteristics of the hybrid combustion boundary layer are the velocity profile and boundary layer thickness along fuel grain length. 
An equation that relates the flame position in the boundary layer to local oxidizer-fuel ratio $\mathrm{O} / \mathrm{F}$ and thereby determines the value of velocity ratio $\varphi_{f}$ (ratio of the velocity at the flame zone to the boundary layer edge velocity), can be shown as follows [2].

$$
\varphi_{\mathrm{f}} \equiv \frac{\mathrm{u}_{\mathrm{f}}}{\mathrm{u}_{\mathrm{e}}}=\frac{(\mathrm{O} / \mathrm{F})\left(\frac{\Delta \mathrm{h}}{\mathrm{h}_{\text {veff }}}\right)}{\mathrm{K}_{\mathrm{ox}_{\mathrm{e}}}+\left[(\mathrm{O} / \mathrm{F})+\mathrm{K}_{\mathrm{ox}}\right]\left(\frac{\Delta \mathrm{h}}{\mathrm{h}_{\text {veff }}}\right)}
$$

where

$u_{\mathrm{f}} \quad$ velocity at the flame zone,

$\mathrm{u}_{\mathrm{e}} \quad$ velocity at the boundary layer edge,

$\left(\frac{\Delta \mathrm{h}}{\mathrm{h}_{\text {veff }}}\right)$ chemical parameter,

$\Delta \mathrm{h} \quad$ enthalpy difference between flame and fuel surface,

$\mathrm{K}_{\mathrm{ox}_{\mathrm{e}}} \quad$ oxidizer concentration in the free stream (boundary-layer edge).

The velocity at the boundary layer edge, $\mathrm{u}_{\mathrm{e}}$ is expressed as:

$$
\mathrm{u}_{\mathrm{e}}=\frac{\dot{\mathrm{m}}_{\text {tot }}}{\rho_{\mathrm{g}} \mathrm{A}_{\mathrm{po}}}
$$

The flame position, $\eta_{\mathrm{f}}$ is described as:

$$
\eta_{\mathrm{f}} \equiv \frac{\mathrm{y}_{\mathrm{f}}}{\delta}=\left[\frac{-1+\sqrt{1+2 \beta \varphi_{\mathrm{f}}\left(1+\frac{\beta}{2}\right)}}{\beta}\right]^{7}
$$

where $\mathrm{y}_{\mathrm{f}} \quad$ flame height from fuel grain surface.

Turbulent boundary layer thickness, $\delta$ is given under the form [4]

$$
\delta=0.37 \times \mathrm{R}_{\mathrm{e}(\mathrm{x})}^{-0.2}
$$

where $\quad R_{e}(x) \quad$ Reynolds number at certain axial position "X".

The characteristics of flame position leads to a very complicated interaction of the regression rate with the changing geometry of fuel grain. In general, to predict the behavior from the above equations, it is necessary to determine all these parameters as function of axial fuel grain length and burning time. Likewise, these parameters may be determined as function of the total mass flow $\dot{m}_{t o t}$ at axial fuel position, which includes the oxidizer flow entering the combustion channel at the injector plus all fuel flow generated at the port upstream of that point. Consequently, the local mass flow $\dot{m}_{\text {tot }}$, the flame position and therefore local regression rate, depend on the parameters at all points upstream through the grain port. 


\section{2. 1 Effective Total Gas Flow Rate Parameter}

The total gas flow can be described at any point of the gaseous stream of the combustion products, $\dot{m}_{g}=\mathrm{f}(\mathrm{x})$, which is composed of the rate of head-end oxidizer flow plus the gas evolved from the surface minus the oxidizer consumed in the combustion. This can be described by the following equation [5].

$\dot{m}_{g}=\dot{m}_{o x}+\left(\begin{array}{lll}1 & k_{1} & k_{1} \zeta_{1}\end{array}\right) \oint_{0}^{x} \dot{r}_{f u} P d x$

where

$\mathrm{k}_{1} \quad$ mass fraction constant, volatile with particulate combustion products,

$P \quad$ internal perimeter of fuel grain.

This equation assumes that a completely vaporizing grain produces particulate combustion products. The factor $\zeta_{1}$ accounts for the mass of oxidizer consumed in producing these particles.

Once the regression rate is determined, the fuel flow rate and mixture ratio are calculated as

$$
\begin{aligned}
& \dot{\mathrm{m}}_{\mathrm{fu}}(\text { new })=\sum_{\mathrm{x}=0}^{\mathrm{x}=\mathrm{L}_{\mathrm{fu}}} \rho_{\mathrm{fu}} \dot{\mathrm{r}}_{\mathrm{fu}} \pi \mathrm{d}_{\mathrm{po}}(\mathrm{x}, \mathrm{t}) \Delta \mathrm{x} \\
& \mathrm{O} / \mathrm{F}=\frac{\dot{\mathrm{m}}_{\mathrm{ox}}}{\dot{\mathrm{m}}_{\mathrm{fu}}}
\end{aligned}
$$

\section{2. 2 Effective Port Area}

The regression rate equation has been coupled with internal ballistics analysis, to deduce equations that describe the instantaneous port geometry of the grain. The effective port area $A_{p o}$ is the actual port area minus the area occupied by the boundary layer displacement thickness [5].

$$
\mathrm{A}_{\mathrm{po}}=(\pi / 4)\left(\mathrm{d}_{\mathrm{po}}-2 \delta^{*}\right)^{2}
$$

where $\quad \delta^{*}$ the boundary layer displacement thickness given by:

$$
\begin{array}{ll}
2 \delta^{*}=0.21 \mathrm{~d}_{\mathrm{po}}\left(\frac{\mathrm{x}}{\mathrm{x}_{\mathrm{A}}}\right)^{0.8} & \mathrm{x} \leq \mathrm{x}_{\mathrm{A}} \\
2 \delta^{*}=0.21 \mathrm{~d}_{\mathrm{po}} & \mathrm{x} \geq \mathrm{x}_{\mathrm{A}}
\end{array}
$$

where

$\mathrm{x}_{\mathrm{A}} \quad$ corresponds to the merge point of the boundary layers.

Based on the presented mathematical model, a computer program is implemented to predict the hybrid combustion boundary layer parameters during operation. 


\section{EVALUATION OF PROPELLANT PARAMETERS}

There are some fundamental parameters used to be evaluated for each propellant combination. They were introduced in the boundary layer model equations.

The knowledge of some chemical parameters is essential for the evaluation of each propellant combination. An attempt to demonstrate the use of the afore-mentioned equations through a numerical application on the plexiglas-gaseous oxygen propellant is the subject of the following sections.

\section{1 Effective Heat of Gasification}

One of the parameters characterizing the solid fuel is the heat of gasification of the binder, which represents the total amount of heat necessary to convert the solid fuel grain at room temperature to its vaporized state at the temperature of regressing fuel surface. The effective heat of gasification for PMMA solid fuel grain $\left(\mathrm{C}_{5} \mathrm{H}_{8} \mathrm{O}_{2}\right)$ can be obtained by summing up the heats needed for the successive processes as shown below $[3,5]$

\begin{tabular}{l|l}
\hline \multicolumn{1}{c|}{ Process } & \\
\hline Heat to raise the fuel from ambient to melting temp., & $\Delta \mathrm{H}_{1}=0.0 \mathrm{~kJ} / \mathrm{kg}$ \\
\hline Heat of liquefaction & $\Delta \mathrm{H}_{2}=543.42 \mathrm{~kJ} / \mathrm{kg}$ \\
\hline Heat to raise the liquid to the boiling point & $\Delta \mathrm{H}_{3}=138.07 \mathrm{~kJ} / \mathrm{kg}$ \\
\hline Heat of vaporization & $\Delta \mathrm{H}_{4}=338.90 \mathrm{~kJ} / \mathrm{kg}$ \\
\hline Heat to raise the vapor to the surface temp. $(\sim 600 \mathrm{~K})$ & $\Delta \mathrm{H}_{5}=468.61 \mathrm{~kJ} / \mathrm{kg}$ \\
\hline Effective heat of gasification of solid phase & $\mathrm{h}_{\text {veff }}=\sum_{\mathrm{i}=1}^{5} \Delta \mathrm{H}_{\mathrm{i}}=1489.0 \mathrm{~kJ} / \mathrm{kg}$ \\
\hline
\end{tabular}

Recorded practical values of the effective heat of gasification of solid phase of PMMA are $1297.04 \mathrm{~kJ} / \mathrm{kg}$ by Marxman [2], and $1464.4 \mathrm{~kJ} / \mathrm{kg}$ by Wooldrige and Muzzy [5].

\section{2 Stochiometric Mixture Ratio, $(\mathrm{O} / \mathrm{F})_{\text {ostoch. }}$}

The local mixture ratio at the flame zone, is fuel rich. It is estimated as $3 / 4$ of the stochiometric mixture ratio and considered to be independent of axial position [2]. Depending on the nature of the propellant, the combustion products will be in the form of molecules $\left(\mathrm{CO}_{2}, \mathrm{CO}, \mathrm{H}_{2} \mathrm{O}, \ldots\right)$, and free radicals $(\mathrm{C}, \mathrm{H}, \mathrm{O}, \mathrm{CO}, \mathrm{HO} \ldots)$. If the temperature exceeds $5000 \mathrm{~K}$, ionized particles will be found [6].

Calculation of the stochiometric mixture ratio is made by assuming that:

1. all the PMMA particles are completely burned by oxygen,

2. combustion products contain mainly $\mathrm{CO}_{2}$ and $\mathrm{H}_{2} \mathrm{O}$.

The proposed combustion equation takes the form: $6 \mathrm{O}_{2}+\mathrm{C}_{5} \mathrm{H}_{8} \mathrm{O}_{2} \Rightarrow 5 \mathrm{CO}_{2}+4 \mathrm{H}_{2} \mathrm{O}$ The stochiometric mixture is obtained by dividing the oxidizer mass by the fuel mass in this equation. Namely, $(\mathrm{O} / \mathrm{F})_{\text {stochiometric }}=1.92$

Such value is close to the values obtained by Marxman, [2] and Marxman and Gilbert [7], which are 2 and 1.9 respectively for the same fuel and oxidizer combination. The discrepancy may be a result of a better definition of the propellant formulation.

\section{3 Mass Transfer Number $(\beta)$}

The mass transfer number which is a governing parameter in the convective heat transfer equation, can be evaluated from [2] 


$$
\beta=\frac{\mathrm{u}_{\mathrm{e}}}{\mathrm{u}_{\mathrm{b}}} \frac{\Delta \mathrm{h}}{\mathrm{h}_{\mathrm{veff}}}
$$

This equation requires the calculations of both the sensible enthalpy difference between the flame zone and the regression surface and the effective heat of gasification by

$$
\Delta \mathrm{h}=\mathrm{Q}_{\mathrm{r}}-\mathrm{C}_{\mathrm{P}}\left(\mathrm{T}_{\mathrm{s}}-\mathrm{T}_{\mathrm{o}}\right)
$$

where $Q_{r}$ is the heat of reaction per unit mass of reactants. It can be drawn from

$$
\mathrm{Q}_{\mathrm{r}}=\frac{\sum_{\mathrm{i}} \mathrm{v}_{\mathrm{r}} \Delta \mathrm{h}_{\mathrm{r}}-\sum_{\mathrm{j}} \nu_{\mathrm{P}} \Delta \mathrm{h}_{\mathrm{P}}}{\sum_{\mathrm{i}} \nu_{\mathrm{r}} \mathrm{M}_{\mathrm{r}}}
$$

where

$v_{\mathrm{r}} \quad$ mass fraction of reactant,

$\Delta h_{r}(i)$ heat of formation of the reactant,

$v_{\mathrm{P}} \quad$ mass fraction of product,

$\Delta h_{p}(j)$ heat of formation of the product,

$\mathrm{Cp}$ heat capacity at constant pressure of gases at the regressing surface,

$\mathrm{M}_{\mathrm{r}} \quad$ molecular weight of the reactants,

$T_{s} \quad$ regression surface temperature,

$\mathrm{T}_{\mathrm{o}} \quad$ fuel grain deep temperature.

The mass transfer number for plexiglas-gaseous oxygen hybrid system is calculated as follows:

(a) Consider the reaction as $6 \mathrm{O}_{2}+\mathrm{C}_{5} \mathrm{H}_{8} \mathrm{O}_{2} \Rightarrow 5 \mathrm{CO}_{2}+4 \mathrm{H}_{2} \mathrm{O}$ that satisfy the stochiometric mixing ratio $=1.92$. The heats of formation are used in Eq. (14). The resulting heat of reaction per unit mass of reactant is $Q_{r}=7411.9 \mathrm{KJ} / \mathrm{Kg}$

(b) Assume a surface temperature of $600 \mathrm{~K}$, an ambient temperature of the grain of $300 \mathrm{~K}$, the specific heat of the species at the surface is $1.6736 \mathrm{~kJ} / \mathrm{kg} . \mathrm{K}$ [2]. Applying Eq. (13), the calculated enthalpy difference between the flame zone and the regression surface is $\Delta \mathrm{h}=6909.87 \mathrm{KJ} / \mathrm{Kg}$

(c) If a stochiometric reaction is assumed at the flame zone, then the oxidizer concentration at the boundary layer edge $\mathrm{K}_{\mathrm{ox}_{\mathrm{e}}}=1.0$ and the corresponding

temperature $=2600 \mathrm{~K}$ [2]. The calculated velocity ratio at the flame is $\frac{\mathrm{u}_{\mathrm{f}}}{\mathrm{u}_{\mathrm{e}}}=0.6183$

(d) The thermodynamic parameter can be calculated using Eq. (12) $\beta=7.58$.

According to Smoot and Price [9], $\beta=9.3$ for pure plexiglas and $\beta=9.6$ for $80 \%$ plexiglas $+20 \%$ aluminum with oxygen as an oxidizer in both cases. Humble [8] pointed out that this parameter falls within the range between 5 and 15 for most hybrid systems of interest. 


\section{4 The Radiation Parameter (N)}

The functional form of the radiation parameter $\mathrm{N}$ in Eq. (1) depends upon combustion products containing particles and combustion chamber pressure. In gas-phase systems:

$\mathrm{N}=\mathrm{nZ}$

where

Z optical path length;

$\mathrm{n} \quad \mathrm{a}$ number that accounts for density of particles in the flame zone, defined as [2] $\mathrm{n}=\frac{3 \lambda}{4 \pi} \frac{\mathrm{k}}{1-\mathrm{k}} \frac{1}{\rho_{\mathrm{g}} \mathrm{r}_{\mathrm{p}}^{3}} \frac{\rho_{\mathrm{e}}}{\dot{\mathrm{m}}_{\mathrm{g}}} \int_{0}^{\mathrm{x}} \rho_{\mathrm{v}} \dot{\mathrm{r}}_{\text {fu }} \mathrm{pdx}$

where:

$\lambda \quad$ mass of particulate combustion products formed per unit mass of nonvolatile surface material

$\rho_{\mathrm{e}} \quad$ density at edge of boundary layer or on motor center line

$r_{p} \quad$ radius of particulate combustion products

The gas density at the edge of the boundary-layer merge point, is related to the edge temperature through the equation of state.

$$
\rho_{\mathrm{e}}=\frac{\mathrm{P}_{\mathrm{c}}}{\mathrm{RT}_{\mathrm{e}}}
$$

The boundary layer edge temperature $T_{e}$ can be adequately described to first order by [2]

$$
\left.\begin{array}{ll}
\mathrm{T}_{\mathrm{e}}=\mathrm{T}_{\mathrm{eo}}+\frac{\mathrm{T}_{\mathrm{r}}-\mathrm{T}_{\mathrm{eo}}}{\left(\frac{\mathrm{x}}{\mathrm{d}_{\mathrm{po}}}\right)_{\mathrm{CR}}} \frac{\mathrm{x}}{\mathrm{d}_{\mathrm{po}}} & \frac{\mathrm{x}}{\mathrm{d}_{\mathrm{po}}} \\
\mathrm{T}_{\mathrm{e}}=\mathrm{T}_{\mathrm{r}} & \frac{\mathrm{x}}{\mathrm{d}_{\mathrm{po}}}>\frac{\mathrm{x}}{\mathrm{d}_{\mathrm{CR}}}
\end{array}\right\}
$$

where

$\frac{\mathrm{x}}{\mathrm{d}_{\mathrm{CR}}}$ length-to-diameter ratio ( $\approx 25$ for most systems),

$\mathrm{T}_{\mathrm{eo}} \quad$ initial boundary layer edge temperature.

Based on the presented mathematical model, a computer program is implemented to predict the hybrid rocket motor boundary layer parameters along fuel grain during operation.

\section{COMPUTATION TECHNIQUE}

The solution strategy that has been adapted to determine the boundary layer hybrid combustion performance history can be described by the following scheme. 


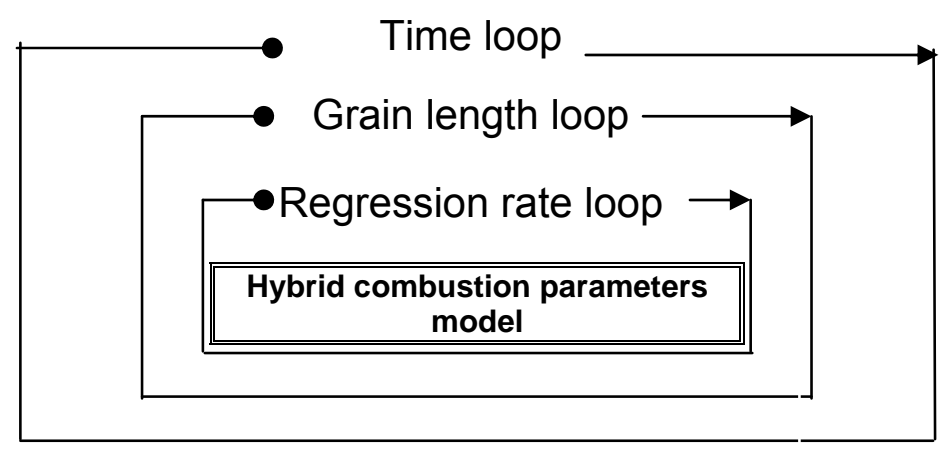

The computer grogram simulates the variation of parameters along fuel grain. During the burning time, at each burning time interval $\Delta t$, the grain length is divided into finite increments $\Delta \mathrm{x}$. Assuming the regression rate constant over each interval $\Delta \mathrm{x}$, the regression rate adds a certain amount of fuel mass flow into the next fuel grain increment length.

During the time loop, at each time increment the following parameters are determined, pressure and port diameter $d_{p o}$ along the grain, its values are updated with the boundary layer thickness and fuel surface regression.

Grain Length Loop, the grain length is divided into a number of distance increments. At each increment, the regression rate can be calculated as will be explained in the following loop. Consequently, the local fuel consumption is readily available for use with the next distance increment. Having completed this loop, it returns the total mass flow rate of fuel. At that point, dividing the oxidizer flow rate by the fuel flow rate provides the mixture ratio. This is the checking parameter that will be used to correct for the pressure allocated in the pressure loop. The approach is explained in the following. In a preparatory stage thermochemical calculations are performed separately using a standard code [11] to establish a matrix array for the $c_{t h}^{*}=f\left(O / F, P_{c}\right)$ For each distance increment $\Delta \mathrm{x}$ the following parameters are determined:

- Fuel grain port area, $A_{p o}$; Eq. (11).

- The regression rate, $\dot{\mathrm{r}}_{\mathrm{fu}}$; Eq. (1).

- Total mass flux, $\mathrm{G}_{\text {tot }}$; Eq. (2-a).

- Mixture ratio, O/F ; Eq. (9).

- Velocity ratio, $\varphi_{f}$; Eq. (4).

- Flame position, $\eta_{f} ;$ Eq. (6).

- Boundary layer thickness, $\delta$; Eq. (7).

- Boundary edge and flame stream velocity $u_{e}$ and $u_{f}$ Eq. (5).

- At the end, the program writes out, the average values of hybrid combustion boundary layer performance and geometry parameters

One of hybrid parameters that is the most difficult to be evaluated is the regression rate of the solid fuel grain. To determine the accurate performance and combustion characteristics during burning time, this parameter should be known as a function of grain length and burning duration.

\section{RESULTS AND DISCUSSION}

The theoretical predicted boundary layer parameters for a hybrid combustion tubular channel have been compared with observations and measurements data from Schlieren photograph of Plexiglas-oxygen flat plate combustion slab burner [2]. 
The characteristics of flame position leads to a very complicated interaction of the regression rate with the changing geometry of solid fuel grain. In general, to predict the behavior from equations 1,4-10 and 11 it is necessary to determine all these parameters as function of axial fuel grain length and firing time, i.e. the total mass flux $G_{\text {total }}$ at axial fuel position includes the oxidizer flow entering the system at the injector plus all fuel entering the port upstream of that point. Consequently, the local $G_{\text {total }}$, the flame position and therefore local regression rate, depend on the value of regression rate at all points upstream of fuel grain length. Furthermore, the local $G_{\text {total }}$ is inversely proportional to the instantaneous local port cross section and also flame height is directly proportional to local fuel grain port cross section. Thus, as the port opening increases during burning, $G_{\text {total }}$ and regression rate tend to decrease as flame height tends to increase.

The effective radiation temperature, $T_{r}$ is estimated as $2 / 3$ of the stochiometric temperature, which can be calculated from thermochemical analysis [11]. The surface fuel grain temperature is assumed to be 600 to $800 \mathrm{~K}$ [2].

The local mixture ratio at the flame zone is known to be fuel rich, and is estimated as $3 / 4$ stochiometric mixture ratio [2]. It is considered independent of axial fuel grain length. The effective wall emissivity $\varepsilon=0.90$ as estimated by Muzzy [2].

The implemented computational program has been used to evaluate the characteristics and performance parameters of hybrid combustion BL, such as boundary layer velocity $u_{e}$, velocity ratio $\varphi_{f}$, flame position $\eta_{f}$, flame velocity $u_{f}$, boundary layer thickness $\delta$, the corresponding mixture ratio $\mathrm{O} / \mathrm{F}$ and flame height $\mathrm{y}_{\mathrm{f}}$.

The performance parameters of hybrid rocket motor is also applied to a cylindrical port and compared with results from a tube burner [1], good agreement is demonstrated in both cases.

The program of hybrid rocket motor performance [1] and mathematical model of boundary layer hybrid combustion have been applied to the case of a hybrid rocket engine, using internal burning fuel grain. The hybrid rocket engine has the following data: oxidizer mass flow rate $=5.5 \mathrm{gm} / \mathrm{s}$ during $20 \mathrm{~s}$, fuel grain length $=150 \mathrm{~mm}$, initial fuel grain port diameter $=5 \mathrm{~mm}$ and external diameter of fuel grain $=50 \mathrm{~mm}$.

Time and fuel grain length variations of boundary layer hybrid combustion performances are given in Figs. 3 through 11.

Axial and radial variations of boundary layer parameters: fuel grain port radius, regression rate, boundary layer thickness, flame height, boundary layer edge velocity, mixture ratio are shown in Figs 3 through 8 respectively.

The general trend is described the boundary layer parameters increases during burning time and the fuel grain port diameter is continuously increasing as shown in Fig.3 which follow Fig. 2, which means reducing combustion BL velocity as Fig.7, that tends to increasing the combustion BL flame height as Fig. 5 and $\mathbf{1 1}$ which makes minimizing amount of heat transfer to fuel grain surface, hence reducing the solid fuel material evaporated to gases. Finally the flame height increasing during burning time, that makes decreasing in regression rate during burning time as shown in Fig. 4.

\section{CONCLUSION}

Hybrid combustion boundary layer is the main phenomenon leading to major disadvantages of hybrid propulsion: low efficiency of combustion and variation in regression rate during burning time. 
A mathematical model has been implemented to solve and describe the boundary layer hybrid combustion performance parameters with time and along fuel grain length history.

The program was validated through the comparison of predicted and Schlieren photograph of Plexiglas-oxygen flat plate combustion burner.

Comprehensive theoretical investigations on parameters that affect the performance of hybrid motor have been carried out. The effects of flame height and combustion zones on performance have been studied. In general, the following conclusions could be made.

1. the regression rate of hybrid motor is mainly affected by the combustion flame height,

2. low combustion efficiency is met due to the established boundary layer on fuel grain surface during combustion.

3. the regression rate is a weak inverse function of fuel grain length

\section{7: REFERENCES}

[1] Makled A. EL-S., A-N Zayed, Abdalla H. M. and el-senbawi M. A. "Hybrid Rocket Motor Performance Prediction" $11^{\text {th }}$ international conference on applied mechanics and mechanical engineering, MTC, 23-25 November, Cairo, 2004.

[2] Marxman C. A. , Wooldridge C. E. and Muzzy R. J. : Fundamentals of hybrid boundary layer combustion, Heterogeneous combustion, progress in Astronauts and aeronautics, vol. 15, Academic press, New York, 1964.

[3] David W. Netzer " Hybrid Rocket Internal Ballistics", Naval Postgraduate School, Monterey, January 1972.

[4] Maxman, G., C. E. Wooldridge \& R.J. Muzzy, "Fundamentals of Hybrid Boundary Layer Combustion" Progress in Astronautics \& Aeronautics, Vol. 15, Heterogeneous Combustion, Academic Press, New York, PP. 485-522, 1964

[5] Wooldridge C. E. and Muzzy R. J. "Internal Ballistic Considerations in Hybrid Rocket Design", J. Spacecraft, Vol. 4, No. 2, Feb. 1967.

[6] Barrere M. et al., : Rocket Propulsion, Elsevier Publishing Company, 1960.

[7] G. Marxman and M. Gilbert "Turbulent Boundary Layer Combustion In The Hybrid Rocket" Eleventh Symposium (international) on Combustion, 1967, Organised by the Combustion Institute.

[8] Humble,R., Henry Gary N., Larson Wiley J., : Propulsion System Analysis and Design, United States Air Force Academy, 1995.

[9] Smoot, L.D and Price, C.F "Regression Rate Mechanisms of Non-Metalized Hybrid Fuel Systems" AIAA, $2^{\text {nd }}$ Aerospace Sciences Meeting, New York, Jun. 25-25, 1965.

[10] Sutton G. : Rocket Propulsion Elements , Sixth Edition, John Wiley, New York, 1992.

[11] Curt Selph "Computer Program for Calculation of Complex Chemical Equilibrium Composition”, NASA SP-273, United States Air Force Academy, version, July 1994. 


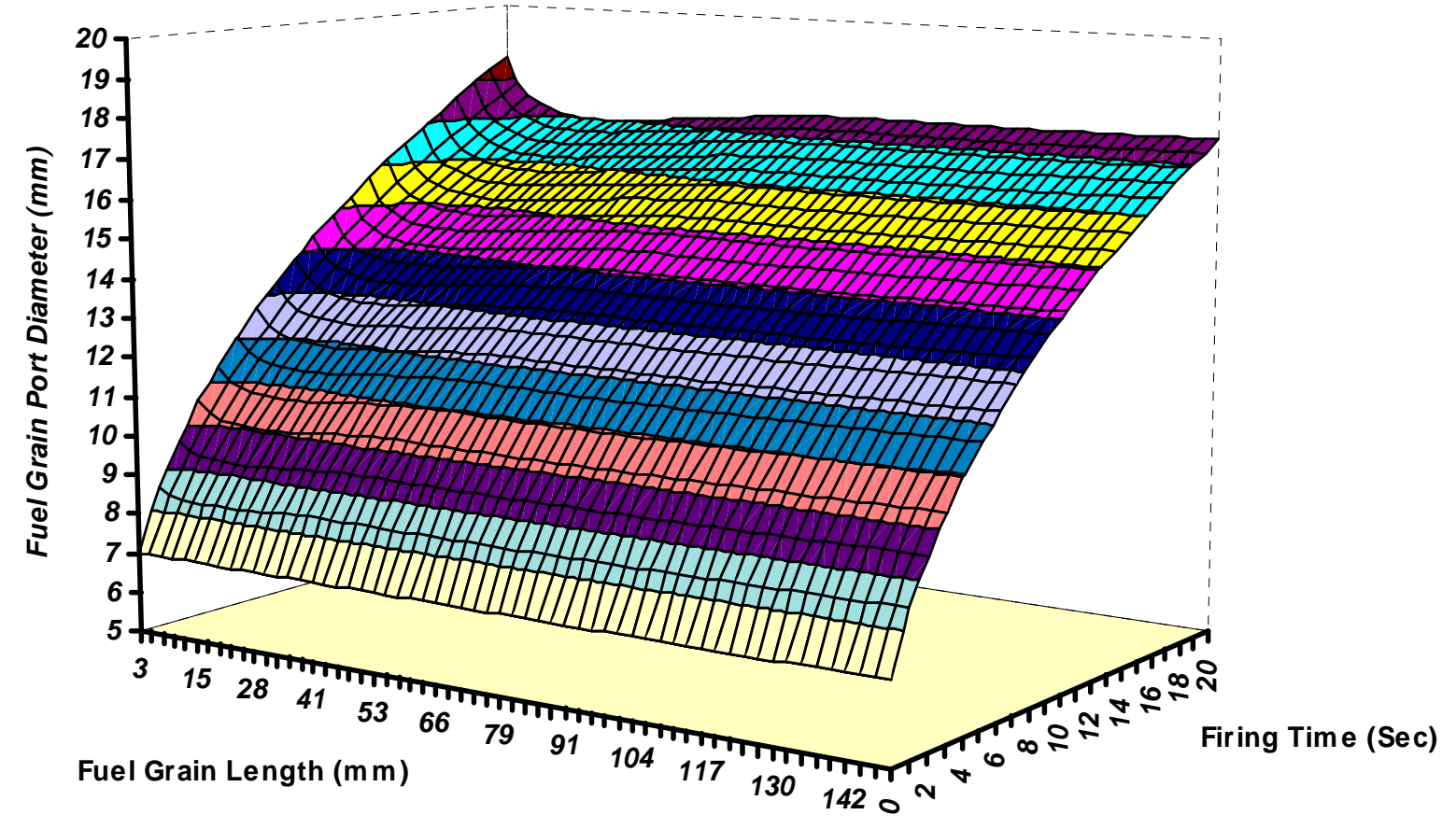

Variation of port diameter along fuel grain during combustion time Fig. 3

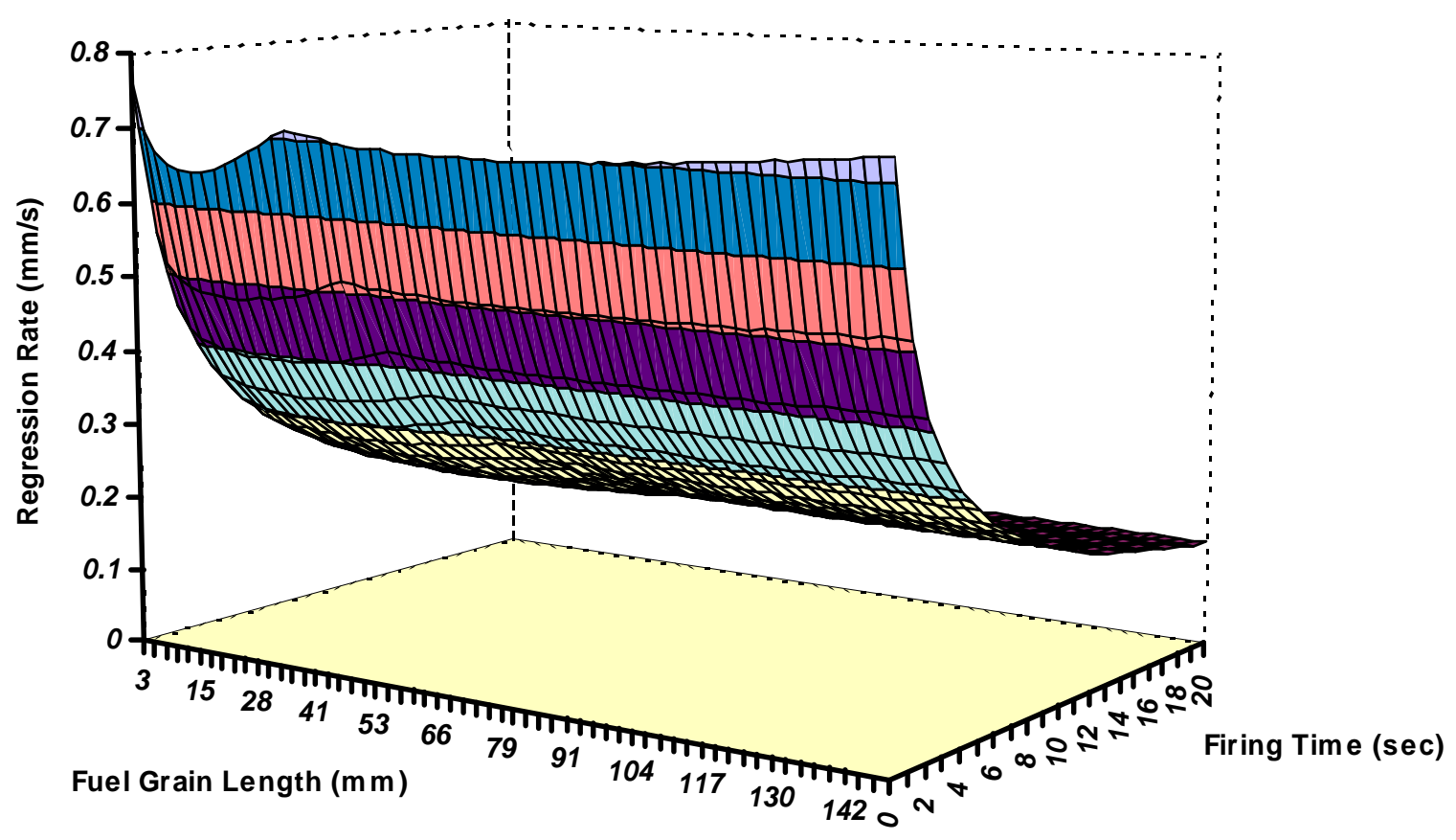

Variation of fuel regression rate along fuel grain during combustion time Fig. 4 


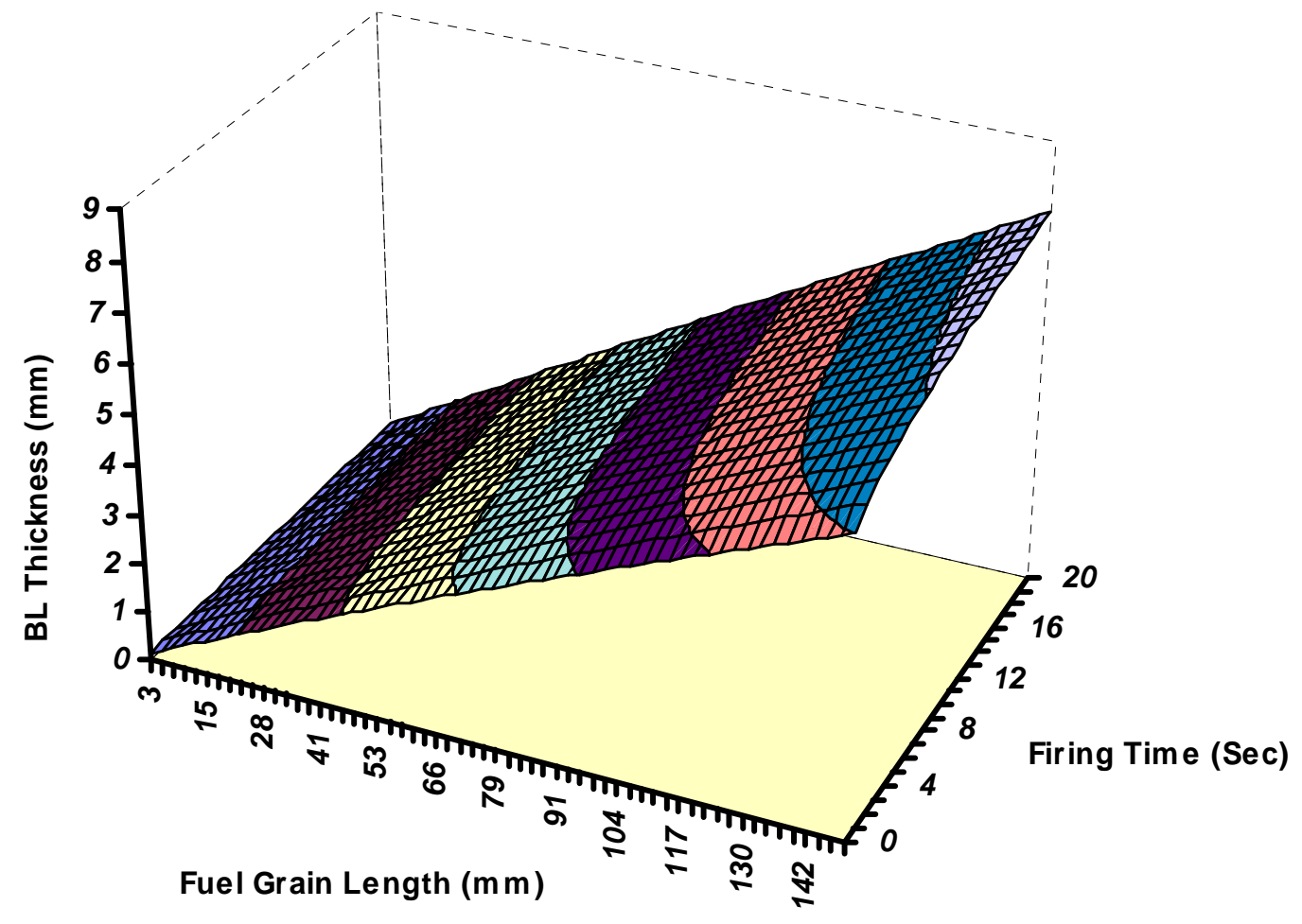

Variation of boundary layer thickness along fuel grain during combustion time Fig. 5

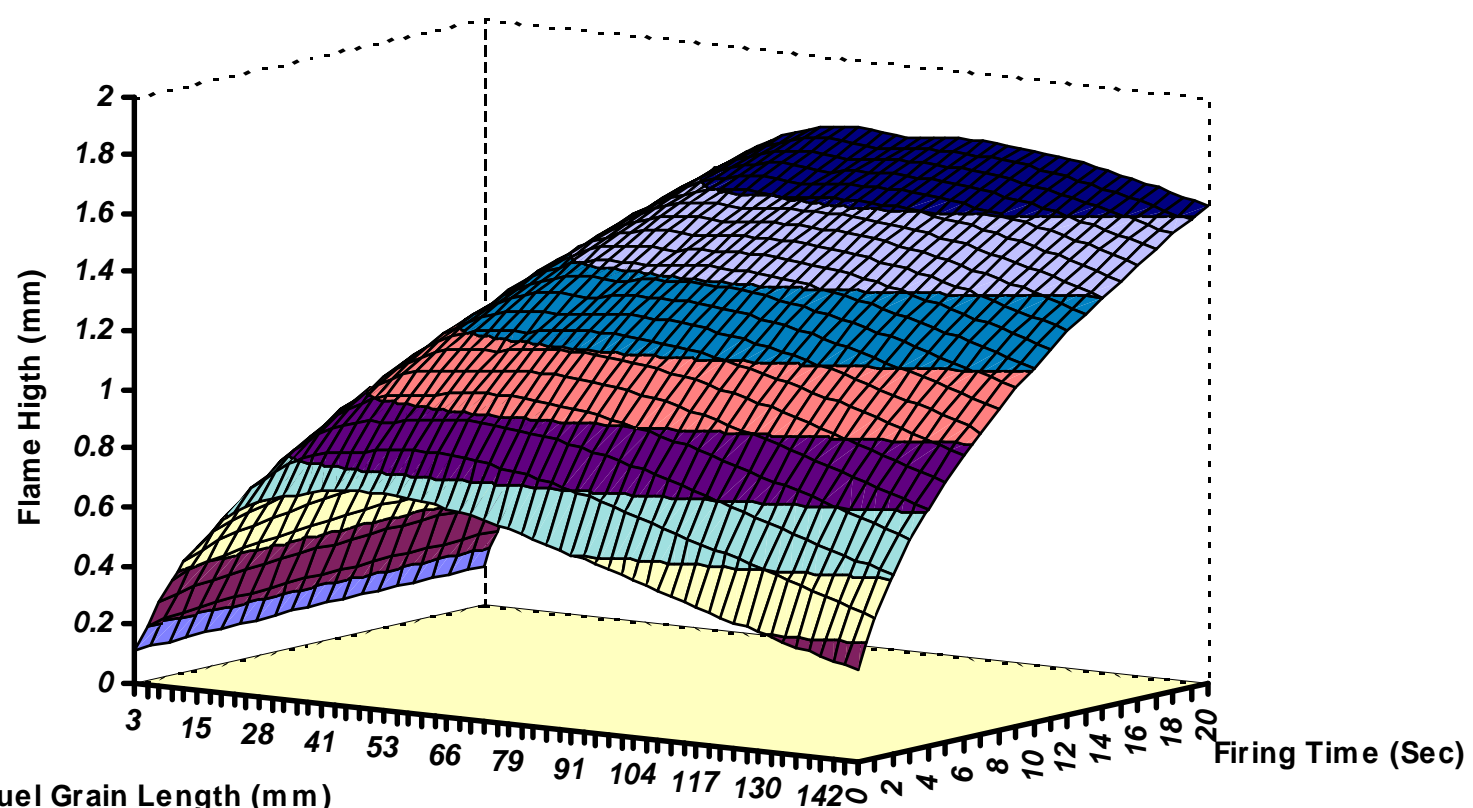

Fuel Grain Length $(\mathrm{m} \mathrm{m})$

Variation of flame position along fuel grain during combustion time Fig. 6 


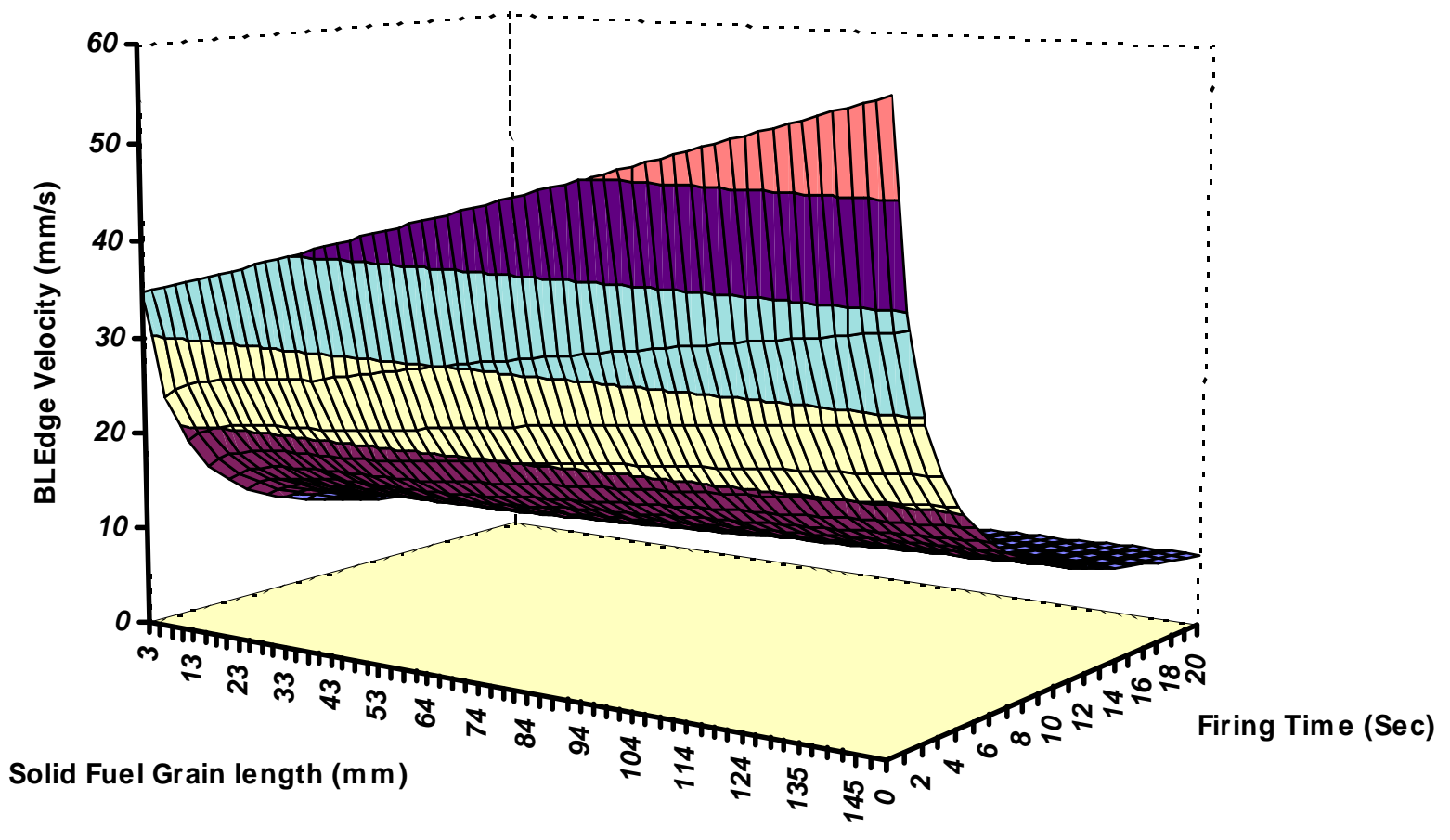

Fig. 7 Variation of boundary layer edge velocity along fuel grain during combustion time

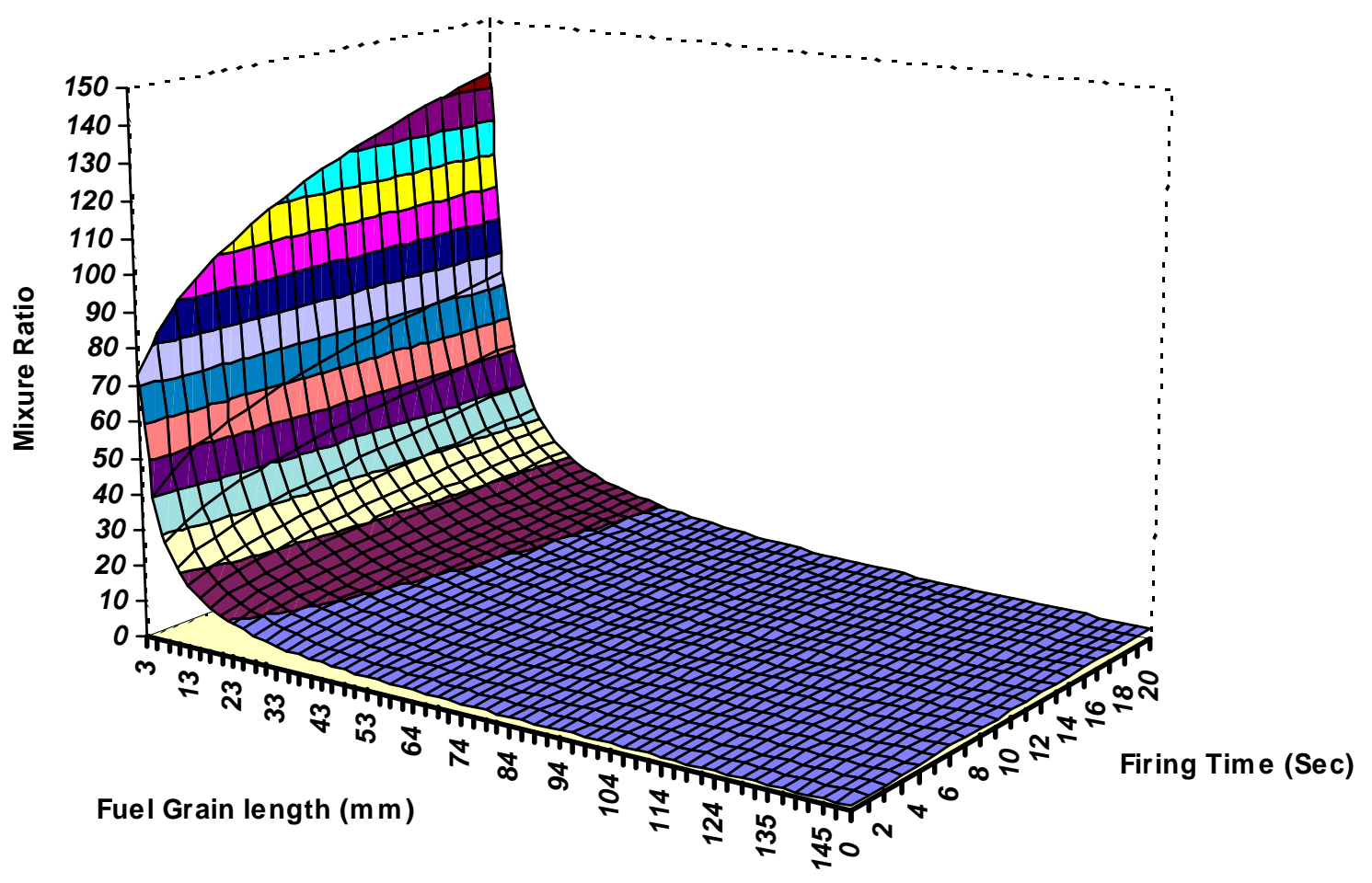

Variation of mixture ratio along fuel grain during combustion time Fig. 8 


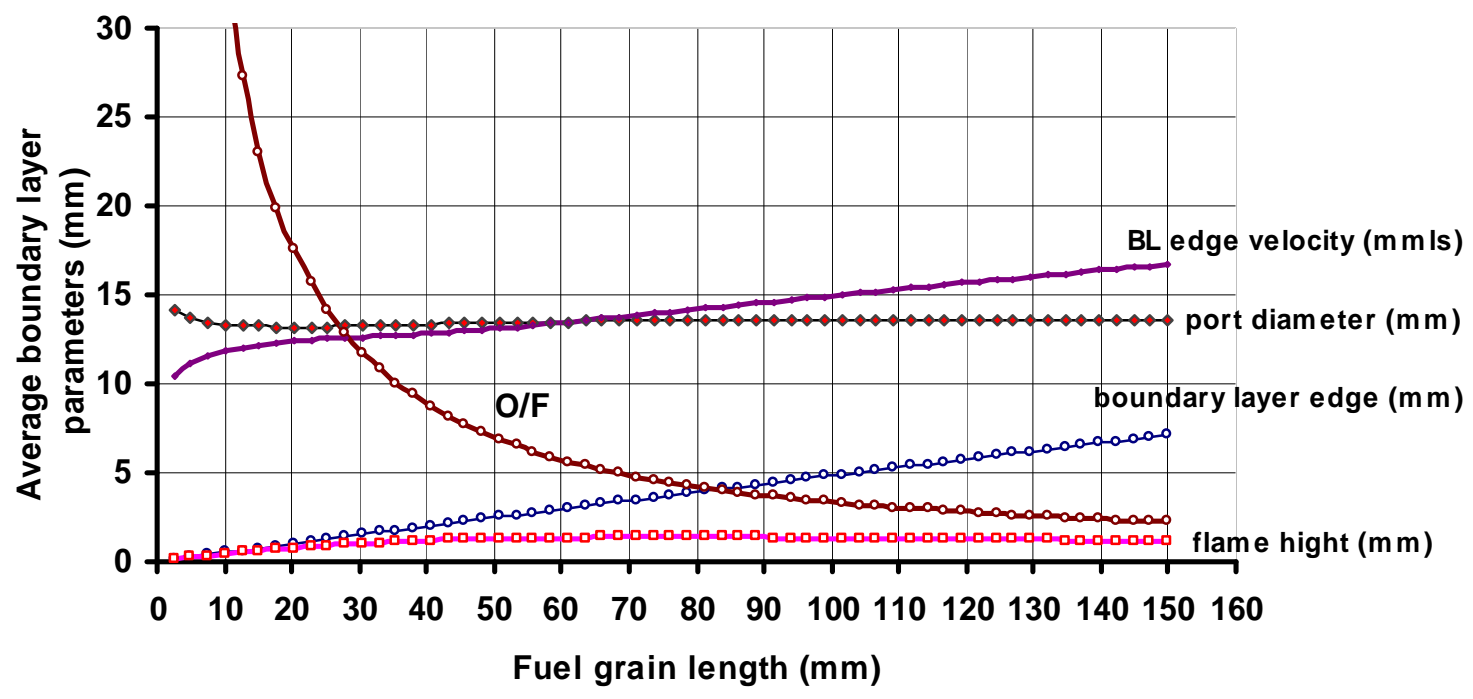

Variation of average boundary layer parameters along fuel grain Fig. 9

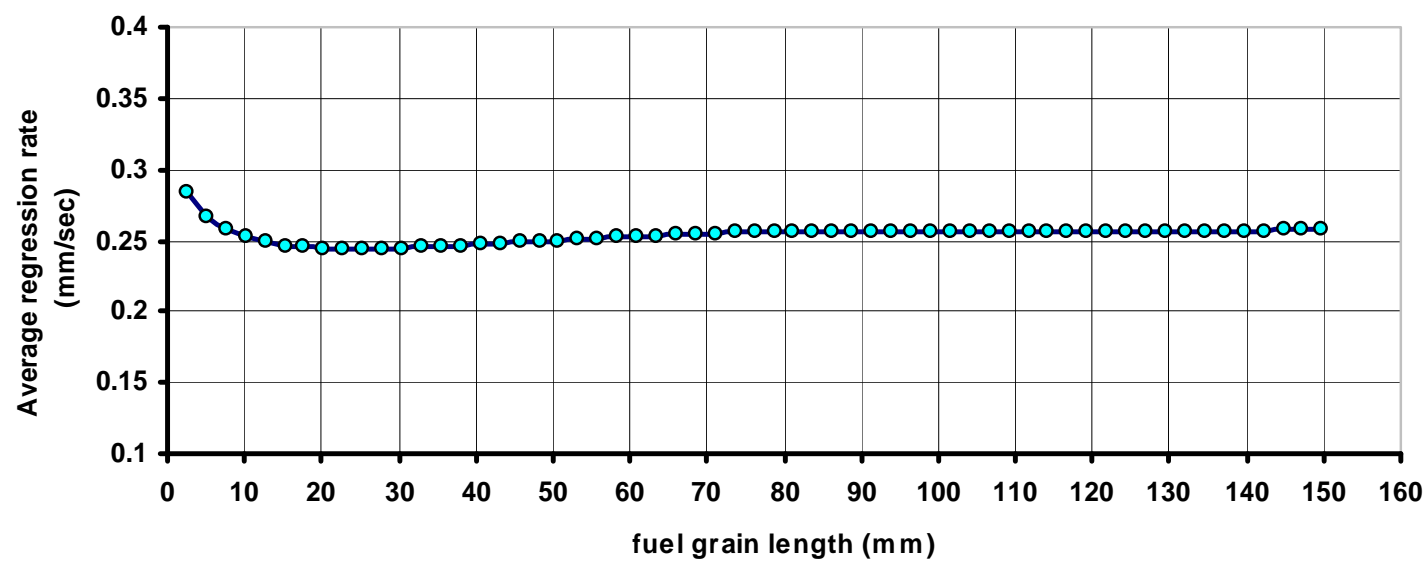

Average regression rate along fuel grain Fig. 10

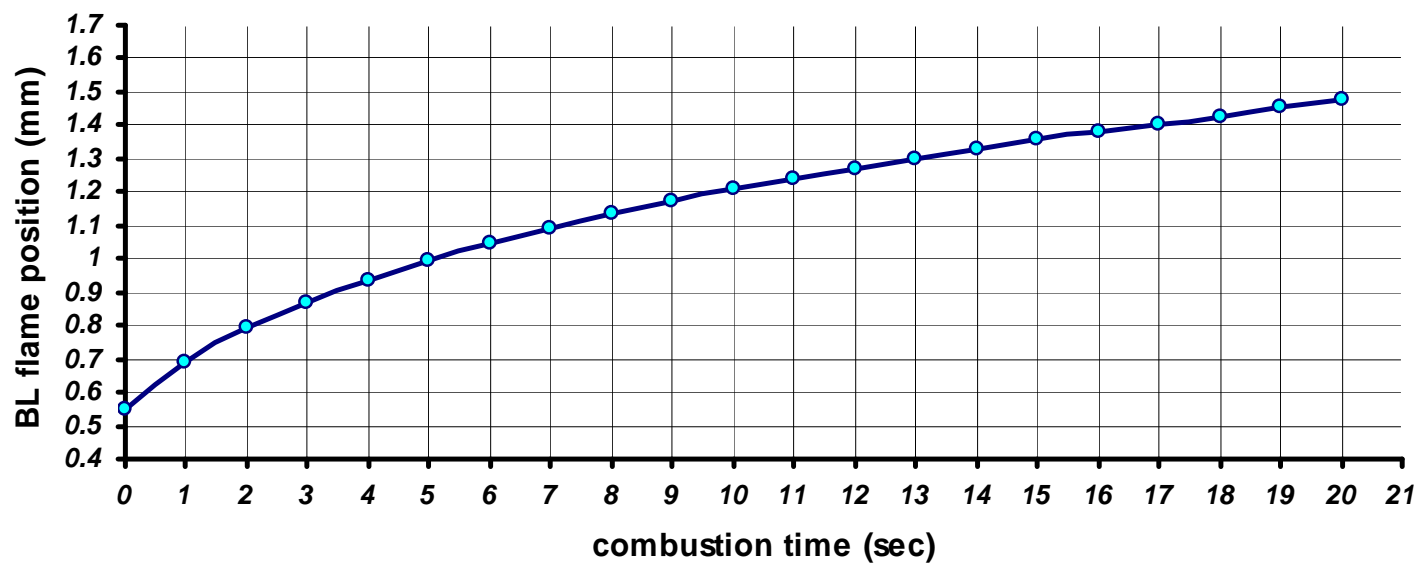

Average flame position during combustion time Fig. 11 